\title{
Evaluation of Satisfaction Survey of Decision-Making Meteorological Services in Shaanxi Province, China in 2017
}

\author{
Huiru Zhi' ${ }^{1}$ Huan Liu' ${ }^{1}$ Yu Jing ${ }^{1}$, Zhenhua Ma $^{2 *}$ \\ ${ }^{1}$ Shaanxi Provincial Meteorological Observatory, Xi'an, China \\ ${ }^{2}$ Shaanxi Provincial Office of Weather Modification, Xi'an, China \\ Email: *mazhina29@163.com
}

How to cite this paper: Zhi, H. R., Liu, H., Jing, Y., \& Ma, Z. H. (2019). Evaluation of Satisfaction Survey of Decision-Making Meteorological Services in Shaanxi Province, China in 2017. Journal of Geoscience and Environment Protection, 7, 126-135. https://doi.org/10.4236/gep.2019.73006

Received: September 20, 2018

Accepted: March 23, 2019

Published: March 26, 2019

Copyright $\odot 2019$ by author(s) and Scientific Research Publishing Inc. This work is licensed under the Creative Commons Attribution International License (CC BY 4.0).

http://creativecommons.org/licenses/by/4.0/

\section{(c) () Open Access}

\begin{abstract}
In China, decision-making meteorological services provide meteorological information for the production organization, disaster prevention and mitigation by the CPC committee, government, military leaders and decision-making departments at all levels, as well as scientific decision-making in the areas of rational development and utilization of climate resources and environmental protection. In order to understand the user's satisfaction with the decision-making meteorological service, the Shaanxi Provincial Meteorological Bureau conducted a statistical survey, and the results showed that: 1) In 2017, the satisfaction level of provincial-level decision-making meteorological services in Shaanxi, China was $92.77 \%$. Among them, the satisfaction index of "Ministry Department Service Personnel Professional Image and Service Awareness" was 94.12\%, and the "Weather Forecast Warning Accuracy" satisfaction index was $90.18 \%$. 2) Decision-making users have become an important channel for obtaining meteorological information through meteorological websites, televisions, mobile phone text messages, APP mobile applications, broadcasting, and Meteorological Information Express. Rainstorms, floods, high temperature heat, cold winds, hail, precipitation, and lightning are still the main concerns of decision-makers. 3) The focus on haze and UV intensity is $15 \%$ and $8 \%$ higher than that of 2016 . The next $1-3$ days weather forecast and 0 - 6 hours short-term forecast are still the most valuable forecast products for decision-making users. Compared with 2016, the next 1 3 days weather forecast, future 0 - 6 hours forecast, traffic meteorology, precipitation probability, and air quality forecast increase by $1 \%$ to $14 \%$ in the year of 2017.
\end{abstract}

\section{Keywords}

Satisfaction, Assessment, Decision Making, Demand, Coverage 


\section{Introduction}

In China, decision-making meteorological services provide meteorological information for the production organization, disaster prevention and mitigation by the CPC committee, government, military leaders and decision-making departments at all levels, as well as scientific decision-making in the areas of rational development and utilization of climate resources and environmental protection (Yu et al., 2018; Zhong et al., 2017; Walmsley \& Gilbey, 2017).

In recent years, extreme weather events in China have occurred frequently (Tang \& Lv, 2016; Chen et al., 2015; Qian et al., 2013), especially in the flood season of 2018. There are many precipitations in the north and heavy rainfall. There are many typhoons and landings, the path is complex and variable, and the forecasting service is more difficult. In the northeast and north China, there is much high-temperature weather that breaks the extreme value, and the pressure of disaster prevention and mitigation is great. Meteorological departments at all levels in the country have always attached importance to decision-making meteorological services. While improving the accuracy of weather forecasting and strengthening the monitoring and forecasting of catastrophic and transitional weather, a standardized decision-making service operation mechanism has been established, and the degree of specialization has been continuously improved (Yang et al., 2017; Fang \& Chiang, 2017; Liu et al., 2017).

Shaanxi is a province of China and the provincial capital is Xi'an City. In the past two years of 2015 and 2016, the overall satisfaction level of Shaanxi provincial decision-making meteorological services has been above $92 \%$. In 2016, the annual satisfaction rate is $92.78 \%$, and the satisfaction rate in 2015 is $92.38 \%$. The above data are provided by the Shaanxi Provincial Meteorological Bureau, China. Overall, meteorological service satisfaction is maintained at an appropriate level. In order to understand the user's satisfaction with the decision-making meteorological service, the Shaanxi Provincial Meteorological Bureau conducted a statistical survey of Evaluation of Satisfaction of decision-making meteorological services in Shaanxi Province, China for the year of 2017.

\section{Survey of Shaanxi Provincial Decision-Making User Group Meteorological Service Survey in 2017}

The survey used a questionnaire survey and a total of 46 copies were collected from the leaders of 27 meteorological disaster emergency headquarters and meteorological disaster emergency liaison officers who participated in the 2017 provincial decision-making meteorological service quality demand survey. These institutions include: Provincial Party Committee Propaganda Department, Provincial Emergency Office, Provincial Meteorological Bureau, Provincial Development and Reform Commission, Provincial Public Security Department, Provincial Department of Finance, Provincial Department of Land and Resources, Provincial Department of Housing and Urban-Rural Development, Provincial Department of Transportation, Provincial Water Resources Department, and 
Province Agriculture Department, Provincial Civil Affairs Department, Provincial Forestry Department, Provincial Safety Supervision Bureau, Provincial Health Department, Provincial Environmental Protection Department, Provincial Military Region, Provincial Armed Police Corps, etc.

\subsection{Position Structure}

There are 14 administrative personnel above the department level, accounting for $30.4 \%$ of the total number of investigations; 32 departmental and general administrative personnel, accounting for $69.6 \%$ of the total number of investigations.

\subsection{Age Structure}

27 people aged 36 to 55 , accounting for $58.7 \%$ of the total number of people surveyed; 18 people aged 20 to 35 years old, accounting for $39.1 \%$ of the total number of people surveyed; one person over 56 years old, accounting for $2.2 \%$ of the total number of people surveyed.

\subsection{Academic Structure}

There are 27 undergraduate students, accounting for $58.7 \%$ of the total number of students; 15 graduate students, accounting for $32.6 \%$ of the total number of students; 3 college graduates, accounting for $6.5 \%$ of the total number of students; 1 high school education, accounting for the total number of students.

\section{Analysis of Shaanxi Provincial Decision-Making User Group Satisfaction Index in 2017}

\subsection{Analysis of 2017 Provincial Decision-Making User Group Satisfaction Index}

In 2017, the overall satisfaction index of the provincial decision-making user group for decision-making meteorological services was $92.77 \%$, which was $0.01 \%$ lower than 2016. Among them, the "predictive warning accuracy rate" satisfaction index was $90.18 \%$, which was $1.30 \%$ higher than that of 2016 , with the largest increase; the "meteorological department's emergency response capacity" satisfaction index was $92.86 \%$, which was second to the increase of $0.90 \%$ in 2016; The satisfaction index of "Timeliness and Release Channels of Weather Forecasts" was $92.79 \%$, an increase of $0.30 \%$ over 2016, and the third increase. The satisfaction index of "Meteorological Department's emphasis on government decision-making services" was $92.83 \%$, down $4.36 \%$ to the maximum; the satisfaction index of "Professional Image and Service Awareness of Service Staff of Meteorological Department" was $94.12 \%$, down $1.87 \%$ to the second; "Weather Information". It is valuable for decision-making work. The satisfaction index is $93.30 \%$, down $1.14 \%$ to the third; the high-impact weather protection service satisfaction index is $92.44 \%$, down $0.79 \%$ to the fourth; "Social and economic benefits of meteorological information". The satisfaction index was 
$93.67 \%$, down by $0.04 \%$ to the fifth. It is worth noting that "the importance of the meteorological department to the government's decision-making services", "the professional image and service awareness of the meteorological department service personnel", "the value of meteorological information for decision-making work", "high-impact weather protection services", and "meteorological information" The five satisfaction indexes of social and economic benefits have declined. Therefore, we must continuously improve our service awareness, enrich our service products, work hard on fine forecasts, and constantly improve our service system (Table 1 ).

\subsection{Quality Analysis of Provincial Decision-Making Meteorological Service Materials in 2017}

In the expression of the terminology of decision-making service materials, $37 \%$ of users chose "comparative", $30 \%$ of users chose "comprehensible", $4 \%$ of users chose "general", and $4 \%$ of users chose "more professional". No user chooses "too professional". Compared with 2016, the proportion of users who choose "more professional" has dropped by $20 \%$ in the year of 2017 , indicating that our decision-making service materials are easy to understand and understand, and the materials are more popular and easy to understand, and accepted by the public.

Table 1. Comparison of expected value (out of 5) and satisfaction value (out of 5) of provincial decision-making meteorological services in 2017.

\begin{tabular}{|c|c|c|c|c|}
\hline & $\begin{array}{l}\text { Expected } \\
\text { value }(\mathrm{E})\end{array}$ & $\begin{array}{l}\text { Satisfactory } \\
\text { value (S) }\end{array}$ & $\begin{array}{l}\text { Gap } \\
(\mathrm{E}-\mathrm{S})\end{array}$ & $\begin{array}{l}\text { 2017/2016 } \\
\text { Satisfaction } \\
\text { Index (S/E) }\end{array}$ \\
\hline $\begin{array}{l}\text { Meteorological department attaches } \\
\text { importance to government } \\
\text { decision-making services }\end{array}$ & 4.85 & 4.50 & 0.35 & $92.83 \% / 97.19 \%$ \\
\hline $\begin{array}{l}\text { Meteorological information is } \\
\text { valuable for decision making }\end{array}$ & 4.87 & 4.54 & 0.33 & $93.30 \% / 94.44 \%$ \\
\hline $\begin{array}{l}\text { Social and economic benefits of } \\
\text { meteorological information }\end{array}$ & 4.80 & 4.50 & 0.30 & $93.67 \% / 93.71 \%$ \\
\hline $\begin{array}{l}\text { Emergency handling capacity of the } \\
\text { meteorological department }\end{array}$ & 4.87 & 4.52 & 0.35 & $92.86 \% / 91.96 \%$ \\
\hline Weather forecast warning accuracy & 4.87 & 4.39 & 0.48 & $90.18 \% / 88.88 \%$ \\
\hline $\begin{array}{l}\text { Timeliness of weather forecasting } \\
\text { and distribution channels }\end{array}$ & 4.83 & 4.48 & 0.35 & $92.79 \% / 92.49 \%$ \\
\hline $\begin{array}{l}\text { Meteorological department service } \\
\text { personnel professional image and } \\
\text { service awareness }\end{array}$ & 4.80 & 4.52 & 0.28 & $94.12 \% / 96.05 \%$ \\
\hline $\begin{array}{l}\text { High impact weather } \\
\text { protection service }\end{array}$ & 4.89 & 4.52 & 0.37 & $92.44 \% / 93.23 \%$ \\
\hline $\begin{array}{l}\text { 17-year provincial decision-making } \\
\text { service overall satisfaction index }\end{array}$ & & & & $92.77 \% / 92.78 \%$ \\
\hline
\end{tabular}


On the question of whether the government decision-making department has established the process of transferring the sub-division of meteorological service information, $89 \%$ of the users choose "the process of batching of strict decision information", and the proportion of users is $34 \%$ higher than that of 2016 , indicating the meteorological service. Materials are increasingly valued by various departments; $2 \%$ choose "not yet established". On the issue of whether decision service information can be delivered to supervisors in a timely manner, 39\% of users choose to be able to deliver quickly.

\section{Analysis of the Demand for Meteorological Services of Shaanxi Provincial Decision-Making User Groups in 2017}

\section{Severe Weather or Meteorological Disasters Closely Related to the Work of Provincial Decision-Making User Groups}

In 2017, the top eight severe weather concerns of the provincial decision-making user groups were: storm floods accounting for $87 \%$, sputum accounting for $74 \%$, high temperature heat damage accounting for $63 \%$, cold wave gale accounting for $57 \%$, hail accounting for $52 \%$, and precipitation. And lightning accounted for $48 \%$, fog accounted for $43 \%$. Dust storms and snow and snow accounted for $39 \%$, frost accounted for $35 \%$, drought accounted for $30 \%$, wind direction wind speed accounted for $26 \%$, Ultraviolet light (Abbreviated as "UV", the same below) intensity accounted for $22 \%$, relative humidity accounted for $13 \%$, and air pressure accounted for $7 \%$. Compared with 2016, heavy rains, floods, high temperature heat, cold winds, hail, precipitation, and lightning are still the main concerns of decision-makers. The attention of haze and UV intensity has increased significantly compared with 2016, with an increase of 15 respectively $15 \%$ and $8 \%$ in 2017 . The decision-making user group has decreased attention to drought, sandstorms, precipitation, hail, cold wind, wind speed, snow and snow depth, air pressure, low temperature frost, fog, lightning, etc. (Figure 1).

\section{Analysis of Meteorological Service Coverage of Shaanxi Provincial Decision-Making User Groups in 2017}

\subsection{The Main Channels for Provincial Decision-Making User Groups to Obtain Weather Information Services}

In 2017, the provincial bureau's decision-making user group obtained the weather information channels. The top six are: meteorological website network accounted for $63 \%$, TV accounted for $61 \%$, mobile phone message accounted for $59 \%$, APP mobile phone application accounted for 57\%, and broadcast accounted for $43 \%$. The Meteorological Information Express accounted for $37 \%$. The official Weibo WeChat accounted for $28 \%$, the Meteorological Information Special Report accounted for $20 \%$, the public display screen accounted for $15 \%$, newspapers and magazines accounted for $13 \%$, and satellite remote sensing information accounted for 9\%. Compared with 2016, the proportion of user groups that obtain weather information through meteorological website networks, 


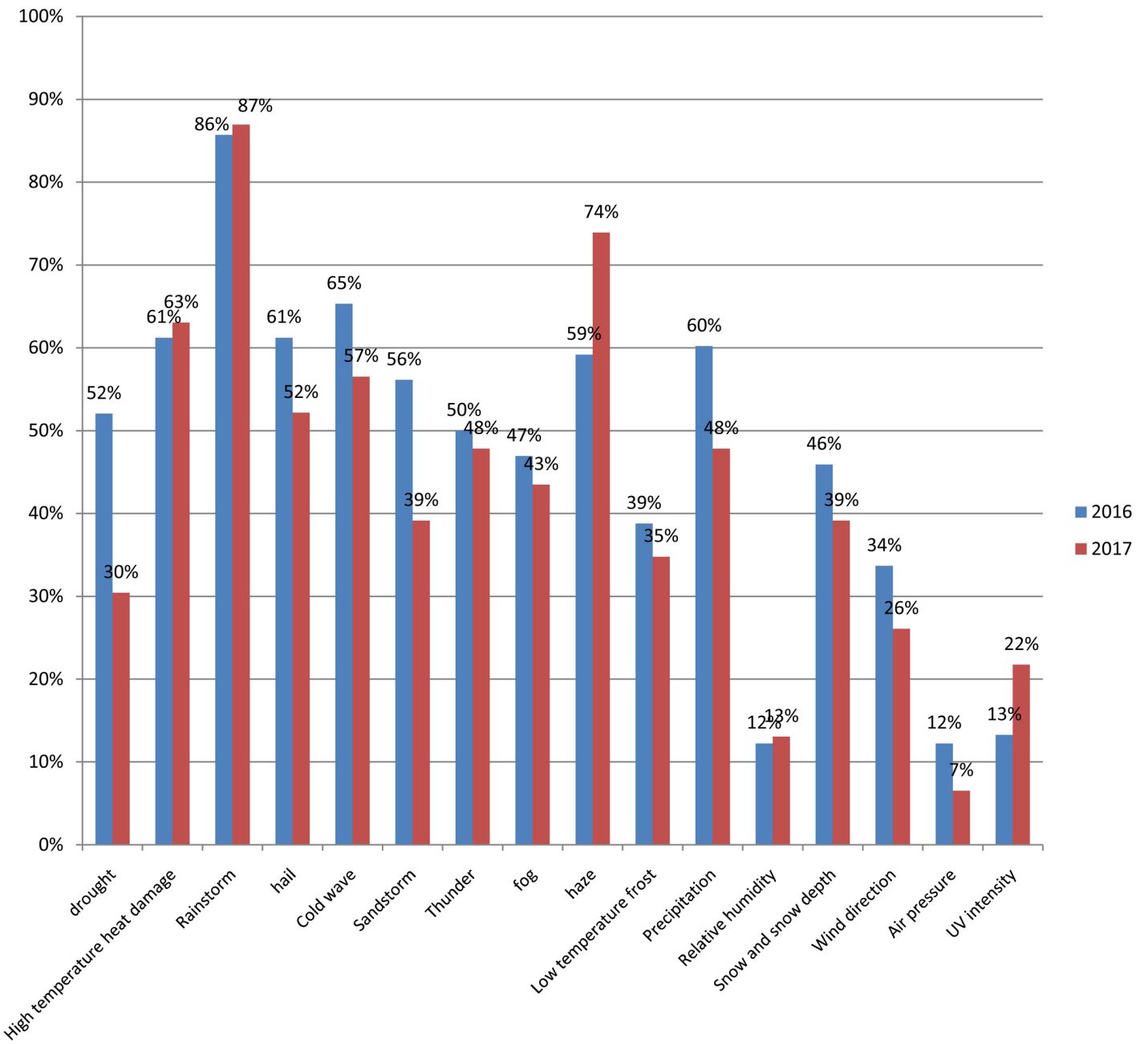

Figure 1. Comparison of weather phenomena that are closely related to work in the 2016-2017 provincial decision-making user group.

TV, APP mobile applications, and broadcasts has increased by $4 \%$ to $12 \%$. Compared with the past three years, the channels for users to obtain meteorological information are still diversified. Meteorological website network, TV, SMS, APP mobile application, broadcasting, and Meteorological Information Express have become important channels for obtaining information (Figure 2).

\subsection{The Purpose of the Provincial Decision-Making User Group to Pay Attention to Meteorological Information}

The purpose of the provincial decision-making user group to pay attention to meteorological information in 2017 is: work production needs accounted for $91 \%$, daily travel needs to account for $85 \%$, disaster prevention and reduction work needs to account for $65 \%$, and early weather prevention $63 \%$ The need to address climate change is $37 \%$. Compared with 2016, the decision-making user group pays attention to meteorological information, except for disaster prevention and mitigation work, which needs to decrease by $3 \%$. This is related to the relatively small and light weather disasters in Shaanxi in 2017; others have improved, 


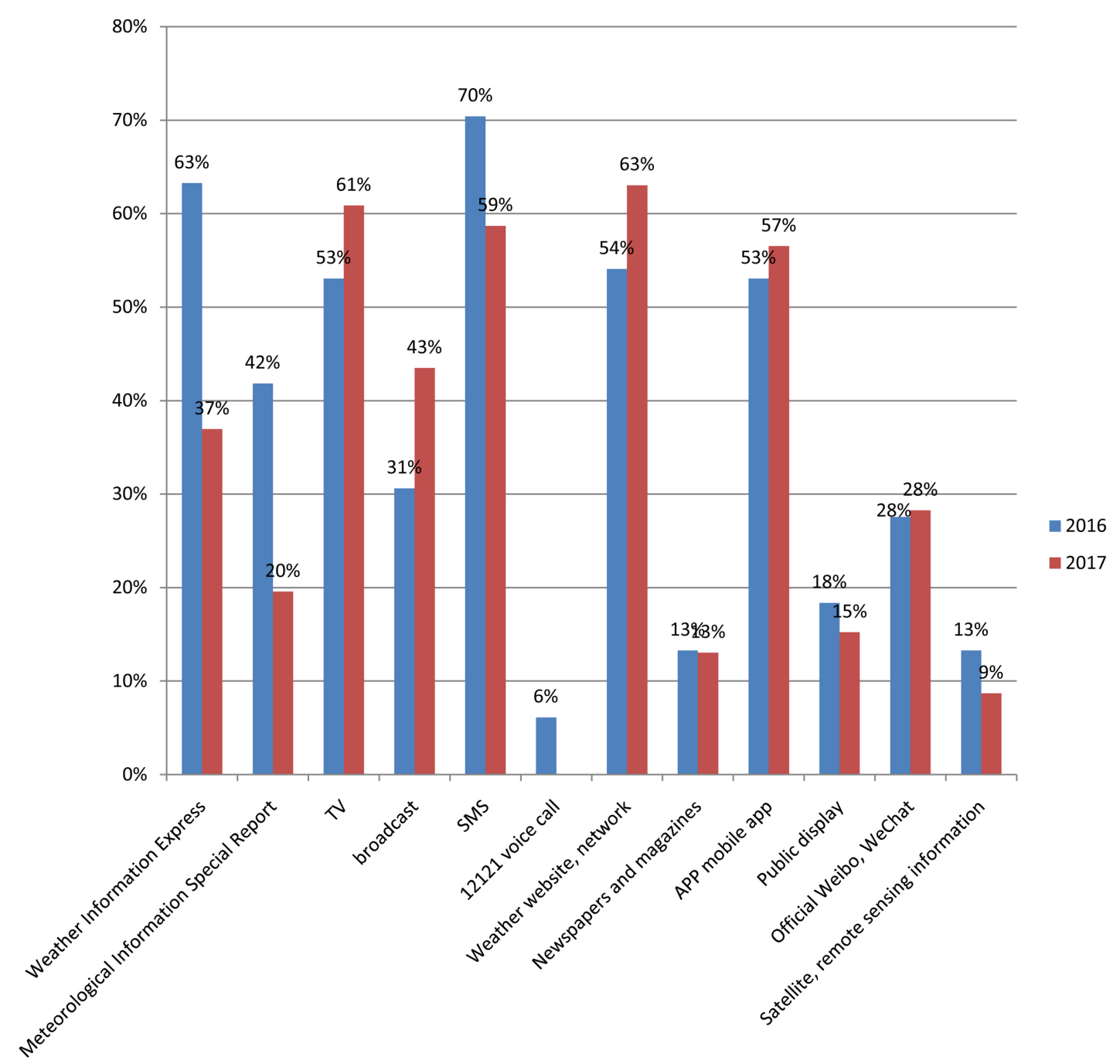

Figure 2. Channel comparison of weather decision information for provincial decision-making user groups from 2016 to 2017.

in order: daily life Travel increased by $26 \%$, work production needs to increase by $18 \%$, climate change needs to be increased by $7 \%$, and early weather prevention is improved by $4 \%$.

\subsection{Suggestions for the Improvement of Meteorological Decision-Making Services by Provincial Decision-Making User Groups}

In 2017, the suggestions for the improvement of meteorological decision-making services by the provincial government decision-making user groups were as follows: the meteorological services were more diversified, accounting for $87 \%$, the disaster prevention and mitigation promotion and training accounted for $72 \%$, and the increase in meteorological knowledge was increased. \%, meteorological modernization construction accounted for 39\%, meteorological news reports or feature films accounted for $37 \%$, expert lectures accounted for $28 \%$, meteorological laws and regulations popularization activities accounted for $24 \%$, and agri- 
cultural meteorology accounted for $15 \%$.

\subsection{Suggestions for the Work of the Provincial Decision-Making User Group on the Work of the Meteorological Disaster Emergency Headquarters}

In 2017, the provincial decision-making user group recommended that $85 \%$ of the government's multi-sector linkages be strengthened, $67 \%$ of all sectors of society participate together, $63 \%$ of the timeliness of emergency meteorological information is increased, and $54 \%$ of government emergency departments are led and regulated. Ways to improve the quality of emergency meteorological services.

In the evaluation of "multi-sector linkage of government to deal with meteorological disasters and weather disaster prevention and reduction work", $80 \%$ of users think it is very useful, and $20 \%$ of users think it is more useful. This shows that the multi-sectoral linkage of the government has played an important role in handling meteorological disasters and doing a good job in meteorological disaster prevention and mitigation, and has played a better role in "government-led, departmental linkage, and social participation".

When evaluating the "Meteorological Information Express", "Meteorological Information Express" product, 63\% of users think it is very good, and 35\% think it is better.

\section{Conclusion}

In 2017, the satisfaction level of provincial decision-making meteorological services was $92.77 \%$. Among them, the satisfaction index of "professional image and service awareness of service personnel in meteorological departments" was $94.12 \%$, which was $1.87 \%$ lower than that in 2016; the satisfaction index of "weather forecast warning accuracy" was $90.18 \%$, which was $1.30 \%$ higher than 2016.

The proportion of decision-making users who obtain weather information through meteorological website networks, TV, APP mobile applications, and broadcasts is $4 \%$ to $12 \%$ higher than that of 2016 . The channels for users to obtain meteorological information are still diversified. Meteorological website networks, TV, mobile phone text messages, APP mobile applications, broadcasting, and Meteorological Information Express have become important channels for obtaining information.

Rainstorms, floods, high temperature heat, cold winds, hail, precipitation, and thunder and lightning are still the main concerns of decision-makers. The attention of haze and UV intensity has increased significantly compared with 2016, with an increase of $15 \%$ and $8 \%$ respectively. The decision-making user group has decreased their attention to drought, sandstorms, precipitation, hail, cold winds and so on.

The next 1 - 3 days weather forecast and 0 - 6 hours short-term forecast are still the most valuable forecast products for decision-making users. Compared 
with 2016, the ratio of future 1 - 3 days weather forecast, future 0 - 6 hours warning, traffic weather, precipitation probability, air quality forecast will increase by $1 \%$ to $14 \%$, including 1 - 3 days weather forecast and precipitation in the next 1 - 3 days. Probability demand ratio increased by $12 \%$ to $14 \%$, and traffic weather and air quality forecast demand ratio increased by $5 \%$ to $6 \%$.

\section{Discussion}

With the increasing demand for meteorological service means by provincial decision-making users, it is necessary to increase the propaganda and popularization of meteorological knowledge and broaden the distribution channels. Decision-making meteorological service products should be more targeted and sensitive, pay more attention to social hotspots and decision-making needs, improve the decision-making effect of service products, improve the structure and content expression of products, and work hard on refinement to make decision-making service products play a bigger role.

In 2017, the Meteorological Bureau closely followed the demand, focused the impact, and strengthened the role of meteorological decision-making staff; adapted to reform, active docking, and enhanced meteorological decision-making supply capabilities; innovative technology, strengthened research and development, strengthened decision-making service support capabilities, and successfully completed all-round decisions Meteorological service mission.

The year 2019 is the 70th anniversary of the founding of New China. It is also a crucial year for winning a comprehensive well-off society. It is of vital importance to make decision-making meteorological services. The Shaanxi Provincial Meteorological Bureau is fully committed to doing a good job in making decision-making meteorological services. It is necessary to strengthen the basic capacity building of decision-making services, make full use of the achievements of modern meteorological services, expand the field, strengthen the scientific research summary and application of meteorological disaster risk impact and assessment; strengthen the assessment, guidance and notification of business quality, and strengthen the construction of decision-making service talents.

\section{Acknowledgements}

This study was funded by the Science and Technology Research Project of Shaanxi Meteorological Bureau (No. 2016M-8), China.

\section{Conflicts of Interest}

The authors declare no conflicts of interest regarding the publication of this paper.

\section{References}

Chen, G., Lu, E., Peng, C., Hou, Y., Qin, Z., Huang, S., \& Liu, F. (2015). Coordinating Preventive Strategies and Restoration under Extreme Weather Conditions. Journal of 
Power and Energy Engineering, 3, 313-318. https://doi.org/10.4236/jpee.2015.34042

Fang, S., \& Chiang, H. D. (2017). Improving Supervised Wind Power Forecasting Models Using Extended Numerical Weather Variables and Unlabelled Data. Iet Renewable Power Generation, 10, 1616-1624. https://doi.org/10.1049/iet-rpg.2016.0339

Liu, M., Luo, Y., Wang, W., He, J., \& Cui, Y. (2017). Comparison of Three Reference Crop Evapotranspiration Forecasting Methods Based on Short-Term Weather Forecast in Zhanghe Irrigation District. Transactions of the Chinese Society of Agricultural Engineering, 33, 156-162.

Qian, Z., Zhang, Z., \& Feng, G. (2013). Detection of the Process about Extreme Weather Events. Journal of Applied Mathematics and Physics, 1, 6-10. https://doi.org/10.4236/jamp.2013.16002

Tang, X., \& Lv, X. (2016). The Effect of Extreme Climatic Events on Extreme Runoff in the Past 50 Years in the Manas River Basin, Xinjiang, China. American Journal of Climate Change, 5, 15-26. https://doi.org/10.4236/ajcc.2016.51004

Walmsley, S., \& Gilbey, A. (2017). Debiasing Visual Pilots' Weather-Related Decision Making. Applied Ergonomics, 65, 200-202.

https://doi.org/10.1016/j.apergo.2017.06.019

Yang, G., Yin, Y., Li, B., Wang, W., Nan, Z., \& Yang, C. (2017). Investigation and Dynamic Analysis of the Long Runout Catastrophic Landslide at the Shenzhen landfill on December 20, 2015, in Guangdong, China. Environmental Earth Sciences, 76, 13-15. https://doi.org/10.1007/s12665-016-6332-8

Yu, X., Yu, X., \& Lu, Y. (2018). Evaluation of an agricultural Meteorological Disaster Based on Multiple Criterion Decision Making and Evolutionary Algorithm. International Journal of Environmental Research \& Public Health, 15, 612-614. https://doi.org/10.3390/ijerph15040612

Zhong, S., Fang, Z., Zhu, M., \& Huang, Q. (2017). A Geo-Ontology-Based Approach to Decision-Making in Emergency Management of Meteorological Disasters. Natural Hazards, 89, 531-554. https://doi.org/10.1007/s11069-017-2979-z 